\title{
The Role of Culture in Sports Sponsorship: an Update
}

\author{
${ }^{1}$ Sara Keshkar ${ }^{*},{ }^{2}$ Ian Lawrence ${ }^{\infty},{ }^{3}$ Mark Dodds $^{\infty},{ }^{3}$ Erin Morris $^{\infty},{ }^{3}$ Tara Mahoney $^{\infty}$, \\ ${ }^{4}$ Kevin Heisey $^{\infty},{ }^{5}$ Francesco Addesa ${ }^{\infty}$, ${ }^{6}$ David P. Hedlund ${ }^{\infty},{ }^{7}$ Geoff Dickson $^{\infty},{ }^{8}$ Hamid \\ Ghasemi $^{\infty},{ }^{5}$ Abdullah Faruq ${ }^{\infty},{ }^{9}$ Michael Naylor ${ }^{\infty},{ }^{10}{ }$ James Santomier, Jr. ${ }^{\infty}$ \\ ${ }^{1}$ Allameh Tabataba'i University, Tehran, Iran. ${ }^{2}$ Teesside University Business School, UK. ${ }^{3}$ SUNY \\ Cortland, Cortland, New York, USA. ${ }^{4}$ Liberty University, Lynchburg, Virginia, USA. ${ }^{5}$ Leeds Beckett \\ University, Leeds, West Yorkshire, UK. ${ }^{6}$ College of Professional Studies, St. John's University, New \\ York, USA. ${ }^{7}$ La Trobe Business School, Melbourne, Australia. ${ }^{8}$ Payame Noor University, Tehran, Iran. \\ ${ }^{9}$ Auckland University of Technology, Auckland, New Zealand. ${ }^{10}$ Sacred Heart University, Fairfield, \\ Connecticut, USA.
}

Submitted 07 August 2018; Accepted in final form 07 October 2019.

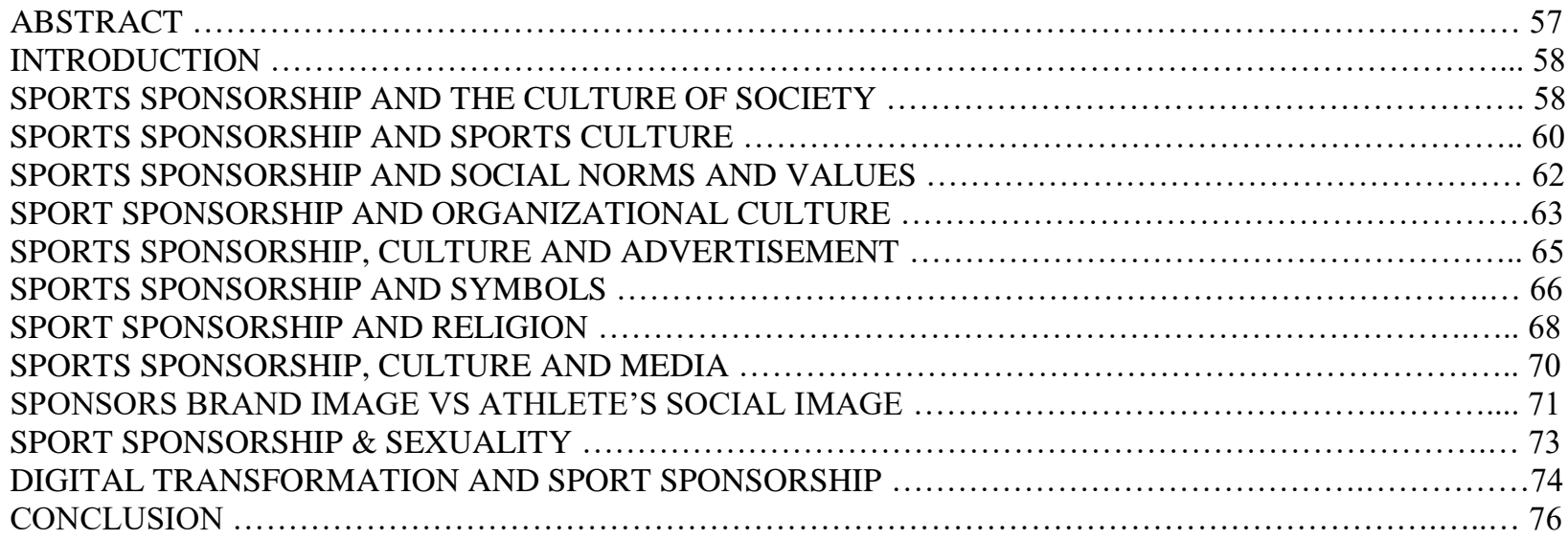

\begin{abstract}
Nowadays sponsorship is an important part of sports events. Sports sponsorship offers more benefits, more variety and also it's a more powerful form of marketing. In general, sponsorship holds a unique position in the marketing mix because it is effective in building brand awareness, provides different marketing platforms and valuable networking and hospitality opportunities. Sponsorship marketing efforts can be influenced by culture. Especially when global sponsorship in sports which refers to sports events in different countries with different cultures, is under consideration. In such situations, sponsorship aspects can be affected by cultural obligations which are discussed in this article.

KEY WORDS: Sports, Sponsorship, Culture, Society, Social Norms, Social Values, Organizational Culture, Advertisement, Symbols, Religion, Media, Sponsors, Brand Image, Athlete, Social Image, Sexuality, Digital Transformation.
\end{abstract}

\footnotetext{
*. Corresponding Author:
}

Sara Keshkar, Associate Professor

P.O. Box: 1489684511, Faculty of Sport Science, AllamehTabataba'i University, Shahid Hemmat West, Dehkadeh-y-Olympic, Tehran, Iran. E-mail: keshkar@atu.ac.ir

$\infty$. These authors contributed equally 


\section{INTRODUCTION}

Sports events are extraordinary opportunities for corporations to introduce their brands and products through advertising, advertising that seeks to establish a deeper association with and integration between an advertiser and a sports organization. All these are what sponsors do in sports events. Nowadays we rarely see a sport event without sponsorship. In most local or international sports events, sponsors have an important role and position. For instance, at 2016 Rio Olympics, some mega companies like Samsung, Nissan, Coca-Cola, Visa, and Toyota were sponsors or partners of the event. Olympic sponsorship deals are expensive; companies reportedly pay upwards of $\$ 200$ million for a 4year sponsorship. Plus, there are lots of restrictions in terms of what advertisers are allowed to do during the Games. These restrictions made Budweiser and McDonald's end their deals with the International Olympic Committee in June 2018. It was supposed to last through at least 2020. The moves made by Budweiser and McDonald's are significant because both companies had been with the Games for over three decades (1). So, effective sponsorship needs to cope with restrictions inside and outside of events organizations which mainly include cultural affairs. Culture and its components play very important roles in sponsorship success, such that in some countries some corporations are not allowed to sponsor sports events, including alcohol drinks in Islamic countries or even some sort of advertisement presentation methods should be changed according to the host country's values, i.e. using bare men and women in context of advertisements in many Eastern countries is not culturally acceptable. Despite the events' restrictions, sports sponsorship is a core part of any sport events and for this reason, some organizations start ranking them by analyzing all conversations and engagement levels from brands across news, blogs, forums, Twitter, Facebook, Instagram and comments on YouTube during the tournament and also the volume of brand's name mentions. On the other hand, there are some other organizations which promote through advertising or inform through publicity and for this purpose, many kinds of media including TV, Radio, social media, newspapers, magazines ... are used (2). Sponsors gain a visible and trustful platform in sports events to introduce themselves to the world and attract global society to their brands and products in which culture and its limitations play a vital role.

This article is a combination of research results and attitudes about the role of Culture in Sports Sponsorship. It's written in a coordinated effort by a group of researchers from universities of different countries, each of whom wrote about their scientific achievements in the subject. They studied different aspects of sponsorship and culture and presented their research results and their analysis in a combination of summary articles.

\section{SPORTS SPONSORSHIP AND THE CULTURE OF SOCIETY}

\section{Ian Lawrence}

In 2018, the revenue generated by sponsorship sector represents one of the fastest growing segments within a vibrant global sports industry. According to research conducted by the financial analysts Price waterhouse Coopers (PwC), the global market is projected to reach $\$ 73.5$ billion by 2021 (3). Historically, the first examples of sports sponsorship can be identified as a form of entrepreneurial philanthropy or 'patronage' in which wealthy individuals (sponsor) provided assistance (financial or in-kind) to their favorite athlete or team (sponsee) in return for the 'halo effect' of prestige and status that such an association afforded them amongst their business community (4). In contemporary business vernacular, sponsors aim to 'tap into' the passion, excitement and deep emotional connections that fans have with their teams and in doing so help drive their corporate and commercial objectives. In return, elite sports rights holders are financially rewarded according to their level of popularity and global brand status. By partnering with sports rights holders, business entities strategize that the commercial partnership will enhance awareness of their business, interest, desire and ultimately drive sales. The 'halo effect' that sponsors achieve by partnering with the most popular elite sports teams and leagues is one that can be felt both locally and globally, but should be predicated upon a mutual appreciation of the 'shared value' that the partnership offers. The concept of 'shared value' is nothing new in the business world and for many is a restatement of 
'stakeholder theory' as conceptualized by Freeman and Reed in 1983 (5); however, the value of its use within this paper is in the way that shared value is seen to create 'economic value in a way that also creates value for society by addressing its needs and challenges' (6). While substantial literature has addressed the benefits that sponsors seek from linking with a sports property, relatively little attention has been given to the potential costs (commercial and reputational) sports rights holders risk from entering into such partnerships. This is surprising, given that with the appropriate due diligence and research to establish congruency between both parties, it is possible to anticipate the level and nature of any sensitivity that stakeholders may have towards prospective partners (7).

Marketing is, by design, intended to directly influence the behavior of customers and others by addressing their 'needs' and 'wants'. However, the dilemma for sports rights holders relates to whether their partnership choices and cobranding intentions of prospective sponsors complement their own localized or global fan 'reach' strategy. Consideration of business congruency requires a very clear understanding of one another's customer base, i.e. who they are, where they are, and what are their purchase decision motivations. As such, a sports rights holder's understanding of the collective norms, values, and beliefs of their own fan base will inevitable assist in helping to define perceptions of what is the 'right' and 'wrong' commercial partner for their fan community. Sports teams therefore require a nuanced understanding of the principles and values that govern the actions of their fans if they are to optimize their relationships with their internal and external stakeholders. Given this responsibility, it is somewhat surprising that elite sports teams and their leagues have seemingly embraced a number of controversial partnerships within the junk food', alcohol and gambling industries. A review of those sectors within the UK reveals that the 'Premier League' (widely considered to be the most-followed and best-known elite football league in the world) to have a growing enthusiasm to partner with a private entities within the gambling industry. The first gambling business to sponsor a Premier League club team (Fulham FC partnership with Betfair) took place in 2002, but currently $45 \%$ of the division (9 of the 20 teams) are anticipated to have gambling firms displayed on the front of their shirts for the forthcoming 2018/19 season. The concerns regarding the partnerships evolving between the gambling industry and professional football are focused upon the impact that gambling advertising (via sports partnerships) has upon a key demographic of football fans - children and their raised awareness of both sports gambling and potential attitudinal changes towards purchase intentions.

Sports rights holders self-evidently need to go beyond a tokenistic commitment towards a Corporate Social Responsibility (CSR) and actively consider how to share value and cocreate with their prospective partners. More often than not, sport marketing campaigns appear to add a 'cause campaign' or a charitable donation as a supplementary part of the overall strategy. Though this is a positive move, it is far from maximizing the opportunity and creating shared value. The growth in 'social activism' is evidence of an opportunity for sports rights holders to seek out partnerships which are congruent with their own mission and vision and demonstrate a sincere commitment towards their stakeholders and their brand identity. Most recently, the sports industry witnessed a resurgence of prominent athletes staging demonstrations to raise awareness of various social issues. The concern for rights holders in many instances appears to be the impact that the hyper-politicization of their star athletes efforts have upon the financial 'bottomline' of their business model with sponsors inevitably anxious about associating their brands with an uncertain product. Soon, leagues and players alike will likely have to make a decision about what is most important: The bottom line or social activism (8).

Nelson Mandela said in 2000 at the inaugural Laureus World Sport Awards that "sport has the power to change the world. It has the power to inspire. It has the power to unite people in a way that little else does. It speaks to youth in a language they understand. Sport can create hope where once there was only despair" (9). While there's no doubt that many of us feel strongly about sport's unique ability to affect positive social change, the key question of the moment is, how do we more effectively leverage the billions of dollars spent globally on sport sponsorship to drive more positive impact and societal good? By ingraining the integrity and morality of 
partnership decision making into activations, brands can positively affect global developmental and societal challenges. Just as importantly, they can simultaneously enable their sponsorship spending to lift their brand reputation and create a new dialogue with socially and environmentally conscious customers and fans. Sponsorship in the majority of sport related instances is no longer simply philanthropy; it's a business exchange and in this context, if a sponsorship does not fulfill the moral, ethical and financial objectives of both parties, then it should not be entered into. Profit and societal change are not mutually exclusive in elite sport, but as evidenced over the past year, marrying the two is likely easier said than done. While the activist issues of today might not mirror the issues of tomorrow, it is expected of both sports leagues and player unions to make the governance of, and response to, social causes a key topic in their discussions with their employers.

\section{SPORTS SPONSORSHIP AND SPORTS CULTURE \\ Sara Keshkar}

'Culture is the set of attitudes, values, beliefs, and behaviors shared by a group of people, but different for each individual, communicated from one generation to the next.'(10). Or, as another definition noted that "culture is a fuzzy set of basic assumptions and values, orientations to life, beliefs, policies, procedures and behavioral conventions that are shared by a group of people, and that influence (but do not determine) each member's behavior and his/her interpretations of the 'meaning' of other people's behavior.' (11). The cultural differences can influence consumer behavior in sport or any other industry. Consumer behavior refers to the selection, purchase and consumption of goods and services for the satisfaction of needs and wants. Sport consumer behavior is also a consumer behavior related to the products and services offered in the particular sport and it is deeply influenced by cultural differences (12). Culture, as one of the most complex concepts in human life, has a special role in sports marketing.

The consumer's social class plays a significant positive role in the behavior of consumers of sports products. It was the most important factor affecting sports consumer behavior. The results of research by Anastasiadou and Vafeiadis (2011) showed that social context as cultural base influence consumer behavior. According to their research results, the location of the home (origin) and of the parent's social class and prestige appears to be a cause for the existence of specific attitudes toward the social influence of publicity. Also, they showed that advertising contributes to encouraging groups of people with shared values, attitudes and standards (13). So, if the advertisements effects can be influenced by social context and class, what about the sports with social class and special context characteristics? What kind of advertisements, brands or products can be influenced by sports class or, in other words, which brands or company can be suitable sponsor for upper or lower class sports? As Oxford references shows, the sports of upper classes are more partial to sports such as golf, tennis, and swimming that stress individualism and aesthetics and may be expensive to play for one reason or another; the lower classes typically favor sports like boxing and basketball that stress teamwork and physical strength and do not require as much money for participation. Some sports, such as baseball, are fairly neutral in terms of social class. But it can be different in different countries. For example, in Iran, skiing, golf, tennis, horse riding, paraglider are categorized as high class sports but swimming and some other gym sports can be middle or lower class sports (14). Which suggests that categorizing sports by social class may not be the same in different countries. That means some groups of people prefer to participate in the special class of sports that can satisfy their cultural demands. Social Classification of sports is a sign of different culture in different sports and it's why some researchers believe that in any society, Sport as a subculture includes of many subcultures itself $(15,16)$. As Markovits \& Smith (2007) argued doers and followers can behave differently in different sports. His Hegemonic sports cultures concept does not only differ by geography and history, but also by factors such as gender, age, class, religion, ethnicity and language (15). So it's an important factor influencing companies' decision for sponsoring of certain sports. As mentioned before, if sponsorship advertisements and publicity are influenced by cultural components, then companies should consider different sports 
cultural contexts to use in their sponsorship efforts effectively.

Rolex, as a luxurybrand, is present at the most prestigious events in golf, sailing, tennis, motor sport, and at equestrian tournaments. Given the longevity and strength of these relationships, in its sponsorships, Rolex is seen not merely as a sponsor... but also as a partner in these sports (17). Prestigious sports events are important for Rolex to introduce its luxury products to doers and followers of such sports. It's obvious that Rolex consumer segmentation is focused on a special social class which rarely can be available in lower class sports events. Luxury brands sponsor prestigious sports events and teams as part of their marketing strategy and for this purpose they also hire celebrity athletes as influencers.

On the other hand, there are some mega brands which sponsor sports with lots of participants (doers) and spectators (followers). Companies like: Nike, Adidas, Coca-Cola ... are mega brands but they don't focus just on prestigious sports because their consumers can be from every social class who participate, watch or follow different sports. Nike's sports sponsorship strategy, as a megabrand, is: basic, milestones and main challengers. Sports sponsorship forms part of the core business of Nike, the world's leading supplier of athletic shoes and sportswear. Nike has been aware of this since its creation, and its team has always worked to keep sports sponsorship in line with the company's business strategy. Nike has implemented innovative initiatives and actions that have become an example to follow in both the sportswear industry and the international corporate world in general (18). Nike's marketing strategy rested entirely upon a brand image which is favorable and has evolved into a great multinational enterprise over time. Most of the consumers of Nike's products are mainly sport enthusiasts or people intending to carry some form of physical activity. Nike targets these consumers by agreements between Nike and athletic teams, college's athletic teams etc. for product sponsorship and eventual promotion to the members of these teams. In this way, Nike is able to reach a wide number of consumers and consumers who are more likely to buy (19).

Luxury brands promote their products in ways that rarely can be changed according to different consumer tastes. These brands are luxury because their characteristics are unique and exclusive and only a special group of people can afford to buy and use them. 'Luxury goods' are not 'necessity goods', that is to say, 'luxury goods' are Veblen goods for which the quantity demanded increases as the price increases, an apparent contradiction of the law of demand. Consumers actually prefer more of the good as its price rises. This is a different strategy in contrast to Nike, which has as one of its core promotion strategies is to fulfill different consumer's needs and doing researches to establish the tastes of different groups of people to diversify market through factoring the product promotion is a main target in Nike's marketing strategy (19).

We should admit that, if there are different sports classes with special cultural characteristics, then it's logical to assume different companies' sponsorship efforts in sports won't result in success if matched with the 'wrong' sport. In research conducted on different cultural components in different sports type, Keshkar et al. (2017) showed that values, attitudes, behaviors of athletes and fans in different sports vary. For instance, while wrestlers pay more attention to traditional values and cultural artifacts, football players tend to modern aspects of life and they pay more attention to other nation's culture (16). They have tattoos on their skins, their hair style and the way they wear is more based on popular fashion. Therefore it's wise if companies active in modern products sponsor football but maybe they cannot be successful in sponsoring wrestling events. Perhaps it's the reason why most of sponsors in these recent sports are very different in types of production, services, promotion style... in different countries including United States $(20,21)$. In any event, sponsorship efficiency in regards to the type of sports is a field in which we need more research to show what the right strategy is for the corporation who want to sponsor sports.

Research results and market experiences show that effective sponsorship in sports needs studying in the areas of cultural characteristics of different sports types. Cultural differences in sports can be the main reason for determining what kind of corporation and products can be successful in what sport and also it can show which kind of sponsorship method can result in positive effects. 
Cultural differences embedded not only in doers and followers of different nations, but in different sports within the same nation. Though nation and culture can influence sports culture, it doesn't prove that sports types have similar culture. So, sports cultural differences can be an important aspect for companies to decide about their sponsorship efforts in sports.

\section{SPORTS SPONSORSHIP AND SOCIAL NORMS AND VALUES}

Mark Dodds, Erin Morris, and Tara Mahoney

Typically sport reflects the values of its society. Many cultures use traditional sport or Ethno sport as an intermediary to promote its heritage and societal beliefs. Sport is highly visible and social values are expressed. For instance, Pussy Riot members charged the field during the 2018 World Cup final with statement about the Russian police. Many American football fans attribute the decrease in television ratings to player protests against police brutality. In many ways, sport sponsorship reflects those same values. The NFL player most associated with those protests, Colin Kaepernick has been without an employer despite leading a team to the Super Bowl just a few seasons ago. Professional cyclist, Lance Armstrong, lost virtually every sponsor once he admitted to using performance enhancing drugs during his seven Tour de France victories.

Brands invest in sport properties "to reach marketing goals and objectives" (22). McCarville and Copeland (1994) evaluated sport sponsorship via the exchange theory between sponsors and properties. Here, the authors conclude that each partner contributes something meaningful to the relationship (23). The sponsor provides funding capital and the property provides a reward such as a potential target market.

Consumer groups, such as sport fans, often act with behaviors that are based on a social identity attributes rather than personal identity traits (24). In this manner, a sport sponsorship may be more effective when the consumer perceives the benefits as important to other members of the group because personal possessions can signal group membership (24). Therefore, if a sport fan identifies with a societal group, the fan's purchase behavior may be used to attach to that group. Because of the common interest, fans will purchase the sponsor products because the sponsor supports the same club as the fan.

The exchange of benefits may also lead to an exchange of brand image. Therefore, a brand sponsoring a property expects the goodwill associated with the property to transfer to the sponsor. This is known as the halo effect. Unfortunately, a negative image may transfer. This is known as the horn effect. Crompton (2014) uses the term "reputational risk" for a brand's lowered equity from a relationship with a negative property (25).

Kulczycki and Koenigstorfer (2016) concludes that a host population has a negative impact on perceived corruption of an eventgoverning body. Bribery or grease-payments may be expected as a cost of doing business in some cultures. However, as sport business intersects with these cultures, its influence on sport sponsorship may be drastic. Thus, in order to participate in sponsoring a sport, a brand may feel pressured to conform to the local business culture of bribery. These actions may go against the sponsor's brand values as well as be illegal in many jurisdictions covering the company. The sponsor would need to choose between adhering to the prevailing law or maximize its sponsorship value at the local level. This conflict becomes more common as many sport mega-events are being hosted within nations with a corrupt business culture. (For a more detailed list of corrupt nations, please see Transparency International https://www.transparency.org).

The horn effect influences consumer behavior. Dodds, Rasku and Laitila (2018) observe that sport fans lower purchase intentions for corrupt sponsors and sponsors of corrupt leagues. This is especially true if the corruption directly affects a favorite club, team, or nation. Here, the balance theory suggests the consumers are punishing the corrupt behavior for negatively impacting a favorite property. This might explain why the 2018 FIFA World Cup sponsorship revenue was $11 \%$ less than in 2014 (26).

However, if the corruption is contained at a national or international level, then the high purchase intentions remain for a local club. This outcome reflects the moral justification theory where a person forgives negative behavior due a strong emotional connection, such as a very high level of fan-avidity. 
In order to combat the potential horn effect, many sponsors leverage its sponsorship activities with corporate social responsibility (CSR) initiatives (27). However, consumers receive socially-oriented marketing messages differently depending on who the sponsor (28). Here, the authors concludes that anti-drinking and driving messages were better received from a non-profit organization as opposed to a large brewery. Walker and Hills (2017) recommend that sponsors balance meeting societal benefits while it leverages organizational benefits (29).

The high visibility of sport sponsorship creates a medium where consumers may voice their opinions on social matters. The McDonald's \#CheerstoSochi online activation of its Winter Olympics sponsorship became a virtual soapbox for consumers expressing their disagreement with the Russian policy against the LGBT community.

Recently, the Papa John's pizza company had many of its sport properties cancel its sponsorship due to offensive comments made by its founder. The properties did not want to be attached to the negative perception created by Papa John's nor did it want to provide a space for protests. By keeping the sponsorship, many fans would assume the sport property condoned the racist point of view.

\section{SPORT SPONSORSHIP AND ORGANIZATIONAL CULTURE}

\section{Kevin Heisey}

In recent decades, sport management has been characterized by increased professionalism. The relationship between sport organizations and sponsors has become increasingly sophisticated and complex (30). Sponsors of sport properties were previously seen simply as revenue sources. The sponsor provided funding in exchange for having their name and logo displayed prominently on signs or shirts. Today, the relationship between sponsors and sport properties has evolved into more of an integrated partnership between the two parties.

A key to successful sponsorships is congruence between the sponsor and the sports property. Elements of congruence are complementary images, shared values, and an overlap in organizational culture. The focus here is on the increasing importance of organizational culture in the sport sponsorship environment.
Organizational culture is considered an important management concept. Every organization has a culture and cultures differ between organizations, but there isn't a clear consensus on how organizational culture is defined. A definition that fits in the context of sport sponsorship is a "shared and learned world of experiences, meanings, values and understandings which inform people, and which are expressed, reproduced and communicated partly in symbolic form" (31).

Sports organizations must cultivate cultures that see potential sponsors as partners. Sport managers should engage with sponsors to understand the sponsor's objectives. They must then be able to assess the tangible and intangible assets associated with their sport property and work to link them to sponsor objectives. Ideally, they should integrate their partner's objectives with their own.

If the sponsor and sport property can develop a shared culture and shared objectives, there is a better chance that their relationship will be sustainable, which enhances the benefits of the relationship (32). Both parties working collaboratively enhances both the immediate and long-term benefits of a sponsorship and results from a collaborative and partner-seeking culture.

Recent literature focuses on the development of the sponsorship relationship away from a transactional one and toward one of partnership and collaboration. The articles below illustrate how sound working relationships can lead to better outcomes. They demonstrate the type of organizational culture required of a sport property to successfully engage with sponsors to achieve sponsor objectives and associated sport objectives.

Nufer and Bühler (2010) stress the emergence of relationship marketing and the growing importance of "positive, enduring, mutually beneficial" relations between sport organizations and their sponsors. Based on a review of related studies, they found five factors essential to sport sponsorship relations; trust, mutual understanding, a long-term perspective, communication, and cooperation. They recommend is that sport organizations devote specific and significant resources, both time and personnel, to sponsor relationships (33). This implies a cultural mindset that sees sponsors as long-term partners in a common endeavor.

To examine the organizational interactions between a sport property and its sponsors, Morgan 
et al. (2004) studied the interaction between a national sport organization responsible for the delivery of an event and four of its sponsors. Interviews with the sponsors indicate that their satisfaction with the sponsorship was based on two key elements; tangible commercial benefits and relationship support within the partnership. They found that strong relationships helped with the formal execution of the agreement and decisionmaking on activation and other issues that arose. Staff turnover was detrimental to satisfaction (34). The sponsors highly valued informal interpersonal relationships with the sport organization feeling they enhanced the ability to manage the formalities of the business agreement. The commercial director of the sport organization indicated that he feels the relationships between people drive successful sponsorships (34).

Jensen and Cornwell (2017) sought to isolate factors that predict dissolution of sponsor partnerships. While they found that external economic conditions play a significant predictive role, they also found that congruence between the sport property and commercial brand lessened the chances of dissolution. Increased clutter in the form of the sport property taking on more sponsor partners made dissolution more likely (35).

Congruence and clutter both point to the importance of relationship management and having a culture that aligns sport property interests with the sponsor partner's. Taking on more sponsors clutters the perception of the relationship as existing partners are no longer one of a few exclusive partners but rather one of many as relationships becomes less clear. Considering the importance of interpersonal relationships found in Nufer and Buehler (2010), and Morgan et al. (2014), additional partners may over-extend and dilute the relationships sport organization personnel have with each individual sponsor $(33,34)$.

The studies cited above highlight the importance of a relational and collaborative mindset between sport properties and sponsors in the modern sport environment. This follows from an organizational culture that includes aligning with and serving the interests of key stakeholders among the main organizational objectives.

A global watershed in the evolution of sportsponsorship happened in the mid-1980s when the International Olympic Committee (IOC) created the TOP ("The Olympic Partners") sponsorship program. While the 1984 Games in Los Angeles were known as being financially successful due to the sale of sponsorship rights, many of the sponsors were dissatisfied. They felt the organizers used them solely as a revenue source coming repeatedly for more money knowing the sponsors wanted the Games to succeed (36).

Following the 1984 Games, when the IOC decided to pursue sponsorship revenue globally, they had to be open to new ways of thinking about sponsor value and activation. The Olympic Games are characterized by clean venues; no signs, boards, brands on uniforms etc. For sponsors to realize value, there had to be innovative ways to think about what assets- tangible and intangibleare associated with the Olympics. To successfully recruit and engage with partners, the IOC had to approach sponsorship with a new mindset that would help them realize the true power and potential of the relationship between sponsors and the Olympic movement (36).

The development of the IOC's TOP program marked a rapid change from an Olympic movement with very little commercial involvement to one of the most successful and powerful global marketing platforms. The new approach trickled down through professional and amateur sports globally over the last 30 years. The main shift is the movement away from the transactional relationship that previously existed to a partner relationship, where both sponsors and sport properties work together to achieve mutual objectives.

The IOC's new culture integrated core elements of its existing culture; i.e. Olympic values and commercially clean venues, with the objectives of potential sponsors. This change in culture ultimately resulted in global sponsorship revenue that has been one of the primary funding sources of the current Olympic movement.

The relationship between sponsors and sport properties has changed significantly in recent decades from a primarily transactional interaction to one of increasing collaboration and complexity. Much of the focus is now on the shared values and culture between sponsors and sport properties. Keller (2008) notes that a sport property's most important assets it can offer sponsors include human and cultural assets such as knowledge of a sponsor's specific information and requirements, teamwork, loyalty to the partnership, and overall reputation (37).

To position itself ideally for successful sponsor partnerships, a sport organization should 
cultivate a culture that seeks to understand sponsor objectives and how the organization's unique assets can be used to achieve them. The organization should seek to engage sponsors with a sense of teamwork, collaboration, and even personal camaraderie. Sponsors should be seen as true partners with sponsor objectives a consideration in all operational decisions.

\section{SPORTS SPONSORSHIP, CULTURE AND ADVERTISEMENT \\ Francesco Addesa}

Sponsorship, defined as "an investment, in cash or kind, in an activity, in return for access to the exploitable commercial potential associated with this activity" (38), and advertising, defined as "a paid, mediated form of communication from and identifiable source, designed to persuade the receiver to take some action, now or in the future" (39) have a symbiotic relationship in the marketing communication mix. This article aims to discuss how sponsoring companies need to deal with cultural habits, traditions and trends when planning advertising campaigns related to their sponsorship deals.

Among the elements of the marketing communication mix, sponsorship and advertising are traditionally considered to have a symbiotic relationship (40). They are different, in a sense that advertising allows marketers to have a greater control over the message sent to the public compared to sponsorship, and the message itself is more direct, explicit and precise (41). But, at the same time, they have to be used jointly to maximize their individual benefits. More specifically, advertising campaigns run before, during and after an event significantly strengthen the link between sponsoring companies and the sponsored event itself, and advertising campaigns may also create or enhance positive feelings towards sponsoring companies, this way increasing the persuasive impact of the sponsorship on the public $(40,41)$.

Even if previous research has found that public's attitude towards TV and Internet advertising has been declining over time (42), Pyun \& James (2011) demonstrated that sport can create a positive attitude toward advertising due to the strong emotional connection consumers create with sport teams and athletes (43). This further increases the incentives for companies to invest in sport sponsorship, as the advertising campaigns implemented in collaboration with the sponsored events or clubs achieve better returns in terms of brand exposure and awareness, especially considering also the exponential potential of social media (43). Therefore, the relationship between sponsorship and sport as a cultural force linked to other areas of social life such as fashion, music, movies, politics (44) must be investigated also through an examination of the interaction between advertising and culture. On the one hand, it is pretty obvious the importance to ensure the adherence of an advertising campaign to the local culture, especially considering the global reach of the sport industry appealing to multinational corporations whose brands are visible in different regions with different habits and social norms. On the other hand, several studies (45-47) have recently focused on the capacity of advertising campaigns to impact on pre-existing social behaviors or to create brand new models of behavior. Our discussion will be based on these particular aspects of the relationship between sponsorship, advertising and culture.

To guarantee the adherence of advertising to local cultures, companies rely on agencies acting as cultural intermediaries able to understand the cultural trends and to find the correct intersections between product, consumer and business. For example, Wieden + Kennedy is the advertising agency behind Nike's unanimously acknowledged creativity and capacity to deliver striking advertising campaigns able to intercept and touch the most meaningful values of local communities. However, to deal with such a delicate matter sometimes leads to controversial outcome, especially when a company tries to contradict well-established stereotypes in conservative regions. The commercial released by Nike in early 2017 and showing Arab women practicing different sports, for instance, attempted to deliver an image different from the stereotype of the home-bound women always associated with that region, but received mixed reactions, with criticisms linked to a not realistic representation of Arab women (48). This is particularly significant if we consider that the next edition of one of the most followed sport events, the 2022 FIFA World Cup, will be hosted for the first time by an Arab country, Qatar. Therefore, the official sponsors of the national teams taking part in the event, or of the event 
itself, will have to plan their advertising campaigns by taking into account a peculiar cultural context that has never hosted any megaevent such as the Olympic Games or the FIFA World Cup itself. The explosion of the Internet and the broadcast of the event on the different nations' TV networks allow sponsoring companies to differentiate their commercials and web ads so as to adhere to the cultural values of the single nations: but what about the on-site advertisements within the host country? For example, how the beer giant Budweiser will operate in a country where it is an offence to drink alcohol or be drunk in public and the local government have intention to set an alcohol ban in stadiums during the World Cup? Will this ban be extended to the display of banners/posters linked to alcoholic beverages companies too? Would Budweiser find an alternative way to advertise their brand, possibly associating it with the launch of a non-alcoholic product, or would they ask for compensation from FIFA?

On top of that, the other aspect to consider is the role of advertising in stimulating or reinforcing particular behaviors in the public either in a positive or negative fashion. For instance, betting companies have dramatically increased their presence in the sport sponsorship market, especially in European football, associating their brands with both teams (through shirt sponsorship deals) and leagues (through naming sponsorship deals) and this way ensuring an enormous visibility among the stadium spectators and TV viewers. But the TV visibility of the betting companies is further boosted by commercials incentivizing gamblers to place a live bet that are continually broadcast by the TV networks before, during and after the game. The overexposure of the betting brands may encourage gambling intentions that can escalate to problem gambling, recognized as a significant public health issue in many countries. If we consider that football is particularly popular among the younger parts of the population, this may lead to the rise of a dangerous cultural trend, which is the reason why, for example, the Italian government decided in July 2018 to ban the advertisement of any gambling related companies.

From what we have discussed so far it might be concluded that, when planning their advertising campaigns, sponsoring companies, because of the more direct and explicit nature of advertising itself, need a greater sensitivity to the cultural traditions and trends of a country or region compared to other elements of the marketing communication mix. On the one hand, the global reach of sport and the connected penetration of new emerging markets, leading also to the organization of mega-events in new regions, require a strong adherence to the local values and habits; on the other hand, the diffusion of unhealthy behavioral trends linked with the promotion of alcohol, junk food, gambling and the will of the governments to tackle them should persuade sponsoring companies operating in these sectors to consider less aggressive advertising campaigns or to rely on other elements of the marketing communication mix.

The rise and continuous growth of the Internet, especially of the social media, provides sponsoring companies with the opportunity to rely on forms of advertising (social shares, web ads, etc.) different from the traditional ones (commercials, posters, banners, etc.). These new forms of advertising ensure an even higher brand exposure, but are less bound to a specific territory and the related culture and can be voluntarily accessed by the public (other than TV commercials for example, where viewers are delivered a message even if they do not want to receive it). For this reason, sponsoring companies, when planning to integrate advertising into the activities related to their sponsorship deals, should rely more and more on the web-related forms of advertising, which would allow them to achieve a significant brand exposure avoiding the issues related to the lack of adherence to the values of a specific region or to the promotion of unhealthy behaviors.

\section{SPORTS SPONSORSHIPAND SYMBOLS David P. Hedlund}

The basis of sponsorship is that a sponsor (i.e., an individual or group willing to pay or trade resources, goods, services or opportunities) desires to connect with a sponsee (i.e., an individual, group or event willing to receive or trade resources, goods, services or opportunities) in order to undertake an exchange and mutually enhance both of their organizations. One of the most common examples of sponsorship in sport occurs when a sponsor pays a fee to partner with a sporting event. For example, at the 2018 FIFA 
World $\mathrm{Cup}^{\mathrm{TM}}$, seven companies are listed as the highest level sponsors/partners (Adidas, CocaCola, Wanda Group, Gazprom, Hyundai / Kia Motors, Qatar Airways, and Visa; FIFA). For the 2007-2010 time period, FIFA's sponsors/partners paid annual fees in the range of USD \$24 million to $\$ 44$ million dollars (49). The "standard rights package" for sponsors/partners includes (1) use of FIFA's official marks; (2) exposure in and around the stadium in which games are played, in all official FIFA publications, and on the official FIFA website; (3) acknowledgement of sponsors support through recognition programs; (4) ambush marketing protection; (5) hospitality opportunities; (6) preferential access to broadcast advertising; and (7) advertising, marketing and promotional opportunities (50). While there are numerous purposes behind why a sponsor will choose to enter into a sponsorship relationship, one of the most important activities includes the exchange and use of symbols representing both sponsor and sponsee. In this section, we will examine the symbols and representations sponsors and sponsees put forward during sponsorship in order to impact the attitudes, perceptions and behaviors of sports fans and consumers.

As noted by Irwin, Sutton and McCarthy (2008), because corporate marketers often see value in associating with sport organizations, teams, players or events, they use and leverage sponsorship as a means to create awareness, develop brand image, and earn sport consumer loyalty (51). More specifically, for sponsors and their brands, sponsorship creates opportunities to influence consumers' perceptions through the sponsor/brand associating with a highly valued event or organization (41), creating sponsor/brand awareness and recognition (52), enhancing sponsor/brand image (53), creating opportunities for hospitality (54), engaging in socially responsible activities (55), increasing the financial value of the sponsor (56), and influencing the purchase intentions and behaviors of consumers (57). Through many of these processes, symbols are used to communicate which groups are sponsors, what type of sponsorsponsee relationship exists, and often times,

1. Benfica Safety video | Emirates Airline: https://www.youtube.com/watch?v=jAF2hZxdFRE information the sponsors and sponsees desire consumers to know.

As a result, one of the most prominent rights sponsors and sponsees exchange and use are the symbols (e.g., name, logos, marks, likeness) displayed during sponsorship activation (i.e., the process of communicating to consumers which organizations are sponsors). For example, when an individual attends a sporting event or watches on television or through electronic media, the site of the event frequently has signage on which names and symbols of sponsors are displayed. In addition to signage, other activities also frequently occur both inside and outside the event location, in addition to the broadcasting of the event or activity, which also serve to advertise and promote the sponsors. Here are two examples through which symbols are used, manipulated and displayed during sponsorship activation activities.

The SL Benfica + Emirates Airline "Safety Video"

On October 25, 2015, prior to the SL Benfica versus Sporting Lisbon football (soccer) match at Estádio da Luz in Portugal, SL Benfica's sponsor Emirates Airlines engaged in a "viral" activation (as of July of 2018, the video on YouTube ${ }^{1}$ had been viewed more than 3 million times). As described in a press release by Burden-Hamer and Emirates Group (2015),

Moments before the huge derby match against rivals Sporting Lisbon, eight Emirates Cabin Crew made their way to the centre circle of the pitch and proceeded to give a very special Benfica supporter demonstration. Taking their cues from the traditional airline safety demonstration, the eight crew stood facing Lisbon football fans and gave an impassioned, witty and entertaining demonstration on how to support the club, including the placement of a scarf over the shoulders in a sign of "benfiquism" (58).

This sponsorship activation included multiple symbols of both the sponsor and sponsee, including the eight Emirates crew members dressed in their recognizable uniforms, the 
audible narration and flight crew actions which mirrored the same activities displayed in flight safety video prior to airline takeoff, yet were adapted to the context of the football stadium and match (e.g., "This stadium has 32 doors," "The match time will be 90 minutes," "We ask you to put your bags securely at your feet and ensure your electronic devices are put away," "Place the scarf over your shoulders as a sign of 'Benfiquism," and "In event of a goal, scarves will automatically appear from above you. Place the scarf over your head and breathe normally."), the flight crew and SL Benfica fans holding and waving their scarves with pride, and the final message to fans epitomizing the relationship between SL Benfica and Emirates which read: "Connecting Benfica fans around the world. \#HelloLisbon."

\section{Juventus + Jeep ${ }^{\circledR}$}

Beyond the alliteration Juventus and Jeep ${ }^{\circledR}$ brand share, this sponsorship relationship is activated through the use and creation of a number of activities. First, as noted on Juventus.com (n.d.), under a photo of more than 20 Jeep ${ }^{\circledR}$ brand vehicles painted with the signature black and white coloring of the Juventus uniforms, the cobranding indicates that the sponsor and sponsee are:

United by the share values of authenticity, passion and adventure, once again this year, the Jeep ${ }^{\circledR}$ brand and Juventus are ready to team up to conquer every terrain and any challenge that comes their way ... The two icons will unite their tradition, passion and determination to overcome together all the obstacles and reach new important goals." (59).

The display of the Jeep ${ }^{\circledR}$ brand vehicles painted in a style similar to that of the Juventus colors, in addition to the discussion of when the Juventus and the Jeep ${ }^{\circledR}$ brand both undertake their respective functions, each will conquer the terrain and challenges they face, while overcoming obstacles and reaching goals provide written descriptions of the common and essential characteristics which symbolize and epitomize both brands.

Moreover, in the Jeep ${ }^{\circledR}$ brand marketing on Jeep.com (n.d.), additional shared symbols are discussed and shown. First, shown next to a picture of official Juventus jersey with the Jeep® brand logo prominently displayed, the marketing and description note that both symbols indicate "The mark of a champion." In an additional section of webpage, links to photos and videos of the Juventus players and fans with Jeep ${ }^{\circledR}$ branded vehicles indicates the additional intertwining of the two brands. Finally, the website also offers exclusive wallpapers (for the background photo on desktop computers and mobile devices), cover photos, stickers and car hangers that can be saved, copied and/or printed by fans that can be used to show their connection with the team and the Jeep® brand. All of the symbols display various aspects of the sponsor-sponsee relationship between Juventus and the Jeep® brand (60).

During the sponsorship process, sponsors and sponsees engage in an exchange process through which both partners can benefit. Throughout sponsorship activities, symbols are commonly used, displayed and leveraged by one or both partners in order to acknowledge the sponsorship relationship and to attempt to impact consumers attitudes, perceptions, evaluations and behaviors. For example, a sponsor and sponsee will likely hope that after seeing symbols displayed through the leveraging of or related sponsorship activities, consumers will become or be more aware of the goods and/or services sponsors provide, and perhaps through feelings of gratitude, reciprocity or necessity, they will consume those items in greater or more frequent quantities. The symbols displayed and seen during sponsorship provide the basis for consumers' awareness of the sponsor relationship and set the stage for future additional leveraging and activation.

\section{SPORT SPONSORSHIP AND RELIGION Geoff Dickson}

A sponsorship network is created when two or more organizations associate, either directly or indirectly, with a sponsorship property (e.g. event, organization, individual, facility) (61). Thus, sport sponsorship and religion intersect when sponsorship stakeholders have a religious dimension.

There are few studies with an explicit focus on sport sponsorship and religion. The focus on sport sponsorship and religion is much narrower than the more expansive literature on the intersection between sport and religion $(62,63)$. Some argue that there is a deep connection between sport and religion (63), whereas others 
consider that sport and religion are "fundamentally different phenomena" (62).

A religion is a "cultural symbols-system that responds to problems of meaning and contingency by alluding to a transcendent (i.e., superempirical) reality, which influences everyday life but cannot be directly controlled (64). Religious organizations are "collective actors whose central activities concern the organization, production, and distribution of religious or spiritual symbol-systems, collective practices, and private goods" (64). Examples include churches, religious centers, temple communities and prayer groups.

Religious organizations are not commonly sponsors of sport, unless their support for sport participation programs is considered sponsorship. In arguably the only study to take an explicit marketing focus to the link between religion and sponsorship, Lee (2010) provided a critical examination of the Peace Cup, a FIFA sanctioned, 12-team, biennial soccer tournament that is organized by the Koreanbased Unification Church (more commonly known as "The Moonies"). In Lee's assessment, the link between the Unification Church and the Peace Cup "may exhibit a form of sport sponsorship" (65). If this is correct, then most if not all church-based sports participation programs may be considered sponsorship. This resonates with the conclusion of Nite, Singer and Cunningham (2013),"Considering many universities and sport organizations are founded by churches and other religious organizations, studying the logic of religion may prove insightful for sport management [and marketing] scholars" (66).

The link between sport sponsorship and religion may not therefore be direct, we are left to consider the tangential (or indirect) links between sport sponsorship and religion (or religious organizations). Four studies illustrate the tangential links.

The first study was about organizational identity. The research concluded that companies which emphasize employees in their mission statements (as opposed financial outcomes) are more likely to sponsor team sports, entertainment, religious, community, charity and business related activities (67).

The second study established that media coverage of Christian football players in the United States tend to equate an athlete's religiosity with good character (68). Given this finding, it is not an unreasonable leap of faith to suggest that the athletes' character will impact their personal brand, and therefore their effectiveness as a celebrity endorser. This proposition is supported by a study from the predominantly Muslim country of Sudan, where researchers established that a person's religiosity partially mediated both the relationships between celebrities' credibility and the attitude towards the advertisement and purchase behavior (69). The study also found evidence that religiosity correlates negatively with celebrities' credibility and attitude towards advertisement.

The third study highlights that some countries have restrictive laws related to the alcohol consumption, and by extension its manufacture and advertising, including sponsorship. Alcohol is a troubling issue for Muslims. Alcohol consumption and marketing is a sensitive issue for Qatar (a predominantly Muslim nation), FIFA, and its 2022 World Cup sponsors (70).

The fourth study investigated FIFA's reluctance to allow Muslim women to wear headscarves whilst playing football (71). The process was described as an intersection of sport, gender, leadership and religion. FIFA, an organization renowned for protecting its image to enhance its value to sponsors, was keen to present themselves as both apolitical and areligious.

Given the pervasiveness of religion, sport, and sport sponsorship, more studies with an explicit focus on the sport sponsorship and religion might have been expected. There are a number of platforms upon which to address this gap in the literature. Future research should investigate the impact of an athlete's religiosity measured in term of extent (i.e. high, low or non-religious) and or type (i.e. Christian or Muslim) on their personal brand, including it impacts consumer perceptions of the athlete's similarity, expertise, trustworthiness, likeability, and attractiveness. Second, researchers can explore how an athlete's religiosity impacts their attitudes and behaviors towards culturally sensitive team, league and event sponsors. Third, the contribution of religious organizations to the development of more restrictive advertising policies related to alcohol and gambling, both of which are commonly associated with sport through sponsorship agreements. Researchers investigating the sport sponsorship and religion relationship should create research teams with expertise in sports socio-cultural dimensions, sponsorship and religion. 


\section{SPORTS SPONSORSHIP, CULTURE AND MEDIA \\ Hamid Ghasemi}

The development of modern sport is bound up with processes of sponsorship and cultural transformation associated with the media. Many experts believe that media have had the main role in professional sport promotion and publicity. Media has had the main role in local and national identity by their sports delegates in different events. The importance of media and sponsorship in athletic sport make some national and international federation try to attract the media and their audiences for more sponsorship and greater potential for negotiation with them.

Media plays an important role in the marketing efforts of different corporations that sponsor sports and athletes. For this purpose, different media acts and effects in different ways. Advertisers usually consider sports TV programming an effective media vehicle to reach target audiences, especially sports fans. Increasing competition to attract audience attention has not only stimulated the development of creativity and visual technology in the advertising industry but also the rising efforts on planning the right media outlets to reach the target market (72).

Historically, television broadcasting was the main source of revenue for elite sports teams, leagues and sports federations. This is now changing because the Internet creates new possibilities for the distribution and consumption of sporting events. Social media is creating new forms of communication between fans, athletes, teams and sponsors (73). Social Media, today, is among the 'best opportunities available' to a brand for connecting with prospective consumers. Social media is the medium to socialize (74). The new media win the trust of consumers by connecting with them at a deeper level. Community social networking websites are the method to interact socially (75). Social media has witnessed an exponential growth in the new millennium. In the present information age, social media marketing has become a part of doing business. Social media marketing, or SMM, is a form of internet marketing that implements various social media networks in order to achieve marketing communication and branding goals (76).

Mobile technology is also changing the way that fans consume sports content generally, especially at live events. These changes create many strategic challenges and opportunities in sports marketing (73).

Nowadays, Mega companies use mass media to promote and sell their products through sports events. The promotion can be done in various ways; it can either be through classical advertising, endorsement, or any other ways of sponsorship (77). But using each of these promotion methods can be influenced by local or global culture. Moreover, using suitable media to promote or advertise is depended to the culture and law or in other words, cultural based law in many countries. On May 2018, a large number of websites and apps were blocked in mainland China. Most Chinese netizens were unaffected by this internet censorship as the vast majority of blocked websites are non-Chinese in content and language. However, foreigners, expats, and travelers residing within China were often left stranded behind the firewall, unable to access most commonly used apps and websites (78). In addition to China, some other countries including Iran, North Korea, Pakistan, Bangladesh, Cuba, Vietnam, Egypt, Syria and Mauritius banned some social media for their people.

In Iran, banned social media of foreign origin was replaced by national social media. Moreover, regardless of social media basis, culture and law limits the advertising frame for corporations which intend to sponsor sports. In Iran, human are not used as advertising tools in commercial advertisements. The Constitution of Iran is based on Islamic beliefs and values which are embedded in Iranian culture. According to Iranian culture and values, human beings have a special position in Islam. So, using sport heroes in commercial advertisement is not acceptable among Iranians. But, in recent years, international sanctions have put great economic pressure on Iranians and this made a great tendency towards using national products in borders of Iran. In this situation, sports heroes can play a very important role to persuade people to use domestic products as a way to resist international sanctions.

So, culture and law which is based on cultural values can play an important role in the quality and way sponsorship happens in sports events. Maybe this limitation can be replaced by global culture in sports. That is to say, if in national territories, culture and law puts some limitation on sponsors to use special media for advertising 
in a defined cultural frame, but in an international atmosphere, the local limitations can be replaced by other forms of frames which match with sports' global values limitations. Now it seems wise, if a company decides to sponsor sports and athletes, for them to investigate and study the local and national situation and cultural limits to be able to decide how to use media and advertisement to lead their company towards success.

SPONSORS BRAND IMAGE vs ATHLETE'S SOCIAL IMAGE: Sponsors strategy involving the selection and management of an athlete with the right image

\section{Abdullah Faruq}

The connection between sport athlete and sponsors has always been a subject of interest (79) with the media often popularizing and funding sport and providing a leverage for both the sponsors and the athlete in terms of their image (80). The constant demand on sport athletes to be able to perform and interact with the fans, often driven by the sponsors and media, has led to the creation of strong social image in the society for the athlete (81). These sporting celebrities or icons are seen as role models in the society and corporate sponsors are prepared to pay good amount of money to associate their brand image with the athlete's social image and tap into their strong pool of fans $(82,83)$. For example, Le Bron James lifetime contract with Nike which is worth over $\$ 1$ billion is just an extreme example how far a sponsor is willing to go to associate their brand image with an athlete's social image, as James is such role model that even when he hangs up his sizeable shoes children worldwide will still aspire to emulate his magnanimous feats (84).

With the sport industry expected to reach $\$ 73.5$ billion by 2019 , we can expect a significant rise of sponsorship contracts involving corporate business and sport athletes (85). The Sport Business Industry has indicated brand associations with high-profile athletes is financially beneficial to the brand, for example, Stephen Curry's endorsement deal with Under Armour has reportedly doubled the financial value of its brand (86). Further research in athlete endorsements has outlined, that in order for a sponsor to effectively maximize their relationship with a sport athlete, they must carefully choose the celebrities with the right social image who create a better fit with their brand image. When selecting a sport athlete, a sponsor generally considers two things: whether the celebrity has a positive social image perceived by the target market; and whether they are trustworthy thereby lending credibility to the brand (87-89).

Besides generating high sales using an athlete's image, this relationship also allows a company to build reputation surrounding their brand (90). Therefore, it is very important for a company to associate their brand image with an athlete who not only has a positive social image, but also provides the best fit in terms of building credibility surrounding the product (91).

Nevertheless, this strategy is inherently risky, due to the fact athlete who are used as endorsers are human, and are prone to mistakes. The fact these athletes are regarded as role model and closely observed by the society thanks to ever watching media, mistakes made by them always become catastrophic for their social image as well for their sponsors. Recent examples of athletes who became talk of the society due to the wrong reasons includes Tiger Woods in several cases of adultery, 12-time Olympic Gold Medallist swimmer Ryan Lochte for his false robbery claims during Rio 2016, Australian cricketers Steve Smith \& David Warner for cheating during a test match are just a few examples from a list, that is growing quite exponentially. The ramifications of these type of scandals, Tiger Woods lost an estimated \$12 million worth of sponsors from Nike Electronic Arts \& Pepsi Co who also lost over $4 \%$ of aggregate market value, Ryan lost an estimated \$1 million worth of sponsorship when Ralph Lauren, Speedo Airweave and Syneron Candela dropped him, Magellan Financial Group, LG electronics and Asics terminated their sponsorship with Cricket Australia worth in the region of \$27 million in the wake of the cheating scandal, who in terms lost out significantly in the market in terms of their reputation (92-95).

As more and more scandals emerge involving the athletes, the industry has seen more sponsors dropping out and the trend now indicates the transition of the drop to be much quicker than before, indicating the sponsors are now more protective of their image and would not hesitate to take stern action regardless of the athlete involved (96). In light of this growing trend this paper discusses the strategic importance of 
sponsors on bringing in an athlete with positive social image and how they manage this relationship.

\section{Athlete Selection the Key Criteria's}

Chen et al. (2012) state that sponsors face many differing challenges when faced with a scandal involving an athlete, namely selecting the right athlete with the right social image (97). The selection process of an athlete endorsers requires careful strategic consideration with an aim to find an endorser that is most congruent in terms of their image with the brand. Companies aim to select the athlete endorser that fits with the brand identity and image and that can transfer positive image, associations and meanings to the brand (98). As athletes are considered as role models who should have clean social images, there should be no surprise image is regarded as one of the criteria that is considered by the sponsors (99). With the proliferation of the media and internet, an athlete's image is very transparent, moreover sponsors nowadays appoint experts to undertake a detailed background research on an athlete with a clean social image, who would complement the brand image positively (100).

Besides social image, another key criteria that sponsors look for in an athlete is whether he/she is trustworthy, a criteria endorsed by Carlson \& Donavan (2017). In their work, Carlson \& Donavan (2017) argue that for an athlete to complement the positive image of a brand, they have to be trustworthy such that they can create a sense of belief among the target market in relation to the perceived quality of the product/service brand they are endorsing (101). This sense of trust would reflect in positive return on investment namely sales growth and aggregate growth of the market value of the product/service brand.

Even with rigorous checks in the criteria, things can always go wrong. Therefore it is important for sponsors to have strategies to manage any negativity involving the image of the athlete.

\section{Strategic Response Plan of the Sponsors}

Sponsors should ensure strategies are employed so as to guarantee reputation and image are not damaged beyond repair due to any negativity involving their endorser athlete (102). The inclusion of moral clauses has now become an increasing trend and is seen as a crucial element of an endorsement agreement, in order to reduce or avoid the potentially unfavorable consequences of bad behavior from athlete endorsers (95). For example, when Mario Ballotelli moved to AC Milan from Liverpool FC, a good behavior clause was inserted considering his maverick reputation (103).

Another strategic tool a sponsor can use is agreeing on an effective exit strategy, outlining how the brand intends to withdraw from a partnership in the case of an unforeseen negative event caused by the athlete deemed to be detrimental to their social image. An effective exit strategy can avoid the potential transfer of negative associations and image. The timing and scope of the exit strategy can both limit negative image transfer, and leverage the situation creating positive perceptions of integrity and ethics, thereby complementing positivity to the sponsors image (104).

The positive impact of athlete endorsements on a brand is well documented in the sport management literature. While it has been outlined that fit in relation to the athlete image and their credibility is essential for success, but one can't ignore athletes being human and being prone to making mistakes. Therefore, it is important from a sponsor's perspective to manage an endorsement relationship with an athlete with background research and effective exit strategy to withdraw from a partnership in the case of an unforeseen negative event.

As we moved towards the future and expected growth in the sport business industry landscape, we will see more use of athlete by companies to promote their brand. But the fact remains an athlete's image may not always remain clean and there is no guarantee about it, any negative image can prove fatal for a sponsor in terms of their image. Therefore, sponsors need to be better prepared to manage this relationship and leverage a positive outcome whereby, positive image can be leveraged for gain and in times of unexpected negativity image can be managed and restored accordingly.

Further suggestions to this paper involves, undertaking a detailed primary study involving systematic study of existing cases involving athlete scandals and outlining new strategic responses sponsors can undertake to manage the relationship. 


\section{SPORT SPONSORSHIP \& SEXUALITY} Michael Naylor

There are a number of societal dimensions that intersect with the business of sport. One of these is human sexuality - which is the way people experience their bodies, pleasures and desires (105). One important aspect of the business of sport are sponsorships, which are multifaceted relationships between businesses and sport entities which rely on them as a means of survival (106). Although human sexuality is diverse and inevitably linked to sport sponsorship arrangements in some way it is not often discussed in the popular press nor has it featured in published sport marketing research. The importance of considering the intersection of sport sponsorship and sexuality is that sex is everywhere in the modern world (105) and the business of sport continues to be ubiquitous as well. Setting the scene as it relates to sponsorship and sexuality in contemporary sport involves a reflection on contemporary sport contexts in which diverse sexuality is pervasive and the identification of avenues for future research.

Human beings often identify intensely through their sexuality (105) and because psychological connections between sport fans and sponsors is so sought after as well, there is a need to better understand the landscape of diverse sexuality and sport sponsorship. One reason why the intersection of sexuality and sport sponsorship hasn't been discussed extensively in the popular press or academic literature is a perception of market size. It may be that sponsors - although not uncomfortable with sexuality diversity - may rather choose to focus on what they perceive to be larger markets of fans and not those linked to the sexuality of endorsers or fans (107). The extent to which the sponsors of sport engage with sexually diverse market segments depends in part on a perception of the viability of those markets. This phenomenon is referred to as pursuit of the "Pink Dollar".

Human sexuality is often categorized in terms of heterosexuality or through the sexuality depicted in the LGBT acronym (lesbian, gay, bisexual and transgender) although this is regarded as an oversimplification by many. Sport has long been the domain of stereotypically heterosexual business arrangements. This is linked to heteronormativity - the notion that heterogeneous sexuality is preferable. For example, sport sponsors have often used female sexuality to attract the interest of male fans. While the sexuality of women has long been exploited and explored in the context of sportbased heterosexual male market segments (108), far less is known about how the role of more diverse sexuality in sport sponsorship arrangements. In fact, it's the norm that many in sporting contexts do not reveal their sexuality (109) making it difficult to draw any conclusions about its role in the way that sponsorships are managed or received by audiences. This may change however due to the perception of improved conditions for sexual minorities in sport (110).

To this point, most of what is written on the topic of sexuality and sport relates to participant sport and or negative fan behaviors related to elite gay athletes. To date the intersection of sexuality and the business of sport - and specifically sport sponsorship - is yet to be covered in sport marketing literature. Numerous aspects of the intersection of sexuality and sport sponsorship are noteworthy.

One context that has been central to the intersection of sport sponsorship and sexuality is major events catering to sexual minorities including the World Outgames and the Gay Games. In these contexts, sport sponsorship and sexuality directly overlap. However, very little is known about if or how these sponsorship arrangements differ from those events in which sexuality is not an explicit theme. Sponsors often seek stable and traditional sport entities with which to forge relationships. Politics and other issues have plagued sporting events explicitly catering to a sexuality diverse clientele (e.g., the last-minute contraction of the 2017 Outgames in Miami) which will make securing sponsors more difficult in future. In traditional sport contexts, there is some evidence that those who identify as LGBT do not wish their sexual orientation to be overemphasized (111). This may extend to elite athletes serving as endorsers or leveragers of sport sponsorship arrangements and should be explored in future empirical research.

There are numerous other worthwhile avenues to build our understanding of sport sponsorship and sexuality. One is in line with McCormack's (2011) work on themed language (112). If sport is to be the inclusive and equitable environment that is often purported and strived for, the 
language used in conjunction with sponsorship activiation should not have a negative social effect by subtly privileging heterosexuality, but should rather have a positive social effect by promoting inclusiveness around sexuality. This could be tested empirically across sporting contexts through content analyses or even data scraping from the Internet.

Another aspect of sport sponsorship and sexuality that is worth exploring further relates to major events and host nations that are not perceived as "gay friendly". Russia's laws related to "gay propaganda" were brought into the spotlight in conjunction with their recent hosting of the Winter Olympic Games (2014) and the Football World Cup (2018). Major sponsors of that event had to be nimble in preparation for any fallout from athletes or fans as a result of their association with an event host that was linked to discrimination (113). This is likely to even more of an issue in future as homophobia decreases and expectations of organizational prosocial behavior increase. It is important to better understand consumers' perceptions of a lack of diversity acceptance in the context of sport sponsorship. This too could be tested empirically, perhaps through an experimental design in which sponsors are depicted as both sexuality diversity accepting and not.

It's possible that organizations may increasingly seek the goodwill linked to their sponsorship of sexually diverse sport contexts a notion linked to socially responsible practice (114). This could be explored by assessing perceptions of sport consumers and add to what we know about how sponsorship activation is received by audiences. As diverse sexuality becomes more accepted in sport contexts, it is very important that sport management scholars evolve theory and research designs to most accurately explore it including as it relates to sponsorship arrangements. It's unlikely that traditional survey research methods will capture the subtleties of the underlying psychology of this phenomenon. Rather case studies and other qualitative methods may be more effective.

Although still pervasive, there is reason for optimism that homophobia and traditional notions of masculinity are decreasing in sport settings (112). Over time this will likely lead to fans and endorsers expressing sexuality more freely and for these expressions to manifest in business arrangements including sponsorship. Evidence has been generated suggesting that reactions from sport communities to players "coming out" in future will be mostly positive (115) and that may extend to the way in which sexuality diverse endorsers and sponsorship campaigns are received as well. If society increasingly embraces diverse sexuality in future, this sentiment will carry through and be reflected in business arrangements of all type including sport sponsorship.

\section{DIGITAL TRANSFORMATION AND SPORT SPONSORSHIP}

\section{James Santomier, Jr.}

"Digital transformation is the profound transformation of business and organizational activities, processes, competencies and models to fully leverage the changes and opportunities of a mix of digital technologies and their accelerating impact across society in a strategic and prioritized way, with present and future shifts in mind" (116). Innovative enterprises are now: 1) focusing on customer/member outcomes using digital technologies; 2) generating revenue from new digital products and services; and 3) reinventing business models with technology integration across the enterprise. From consumer information to e-commerce transaction information, to corporate inventory and customer data, enterprises require efficient and cost-effective solutions for data storage and data back-up. The purpose of this article to discuss briefly digital transformation in sport and elucidate its significance to sport sponsorship.

Sport enterprises are striving for complete digital transformation as they continue to define "technology's role and impact on leagues, teams, media companies, sponsors and a wide range of other players in this ecosystem" (117). Sport enterprises have embraced digital transformation with the objective of enhancing "the integration between the various touch-points and physicaldigital communication channels, making the processes more streamlined and friction-free for the user, introducing more scalable technologies and platforms to add new revenue sources (118). Therefore, a necessary element of digital transformation for sport enterprises is creating a single platform that connects all digital assets (for example, a team's online store, physical store, website, ticketing system, social networking sites 
(SNS), customer database, and corporate sponsors) to a single database.

The convergence of consumer needs worldwide has necessitated that brands discover unique and effective ways to communicate with sport fans and open new markets. Brands have taken advantage of compelling economic, consumer, and media trends and are leveraging the emotional impact of sport to connect with consumers. However, digital transformation also has changed dramatically the balance of power between customers and brands. Digital technologies have enabled customers to gain the power of information and choice, while brands have improved their business models. The acceleration in the growth of sport sponsorship is due not only to global business complexity and media channel fragmentation, but from a more sophisticated and technologically integrated approach to sponsorship on the part of brands and sport properties. As competition among brands intensifies, sport content - teams, leagues, federations, mega-events, athletes, and celebrity causes will continue to increase in value. In 2018 brands will spend $\$ 147$ billion on sport sponsorship and activation and 70 percent of total sponsorship spend will be in sport. Thus, sport sponsorship is a pivotal dimension of global marketing campaigns for numerous brands and is considered to be as important, if not more important, than traditional marketing strategies.

Digital transformation has impacted emerging markets such as India, Brazil and Russia, where $85 \%, 81 \%$ and $76 \%$ of fans respectively consume sport content online. However, this increase in online viewing is not at the expense of other channels. TV remains the most popular medium, with $94 \%$ of sports fans globally and $95 \%$ in Britain using it to watch sport. This suggests that while digital channels are helping sponsors to reach new audiences, both demographically and geographically, they are supplementing rather than replacing traditional marketing platforms (119). For example, "since its inception, the global reach of the Premier League, which is followed by an estimated 1.2 billion people worldwide, has attracted brands seeking to expand into new markets. With the added impact of digital media, brands are now able to localize their activations to different countries and create a wide range of online content in partnership with rights holders" (119).
Digital transformation also has changed the nature of the marketing mix for sponsors. For example, cross media strategies enable sponsors to engage with fans more directly and demonstrate return on investment (ROI) more clearly. During the 2012 London Olympics sponsors invested over U.S.\$5 billion in activation and media opportunities. In addition to capitalizing on new social media opportunities, they tested new programs "that pushed the boundaries between paid, owned, shared and earned media" (120). Several Olympic sponsors activated using "transmedia storytelling," which evolved with digital marketing and communicates different things within the broader strategy (or story) across multiple platforms and multiple audiences. Another new strategy in 2012 that was popular for Olympic sponsors was the implementation of real-time marketing, which is "the practice of brands engaging their audience via content, advertising, and product placement that is relevant to a specific current event or cultural happening. The content is most often in the form of a "meme" or graphic advertisement shared through social media channels" (121). Olympic sponsors understood that due to changing media consumption patterns, viewing the Olympics via multiple screens ("second screen viewing") meant that each viewer would have his or her own personal perspective on the Olympics. It also meant that the specific platform a marketer selected would determine the content and form of the marketing communication.

Digital transformation has created a proliferation of modes to reach and interact with an audience, which enhances the potential for innovative approaches to sponsorship rights. This may result in sponsorship opportunities allocated on distinct, platform based rights or selling bundles of rights in a comprehensive sponsorship package. Global brands, therefore, are not simply sponsoring sport properties but creating specific strategic sponsorship partnerships through agreements that enhance value creation for sponsors and sport properties.

In 2016, Facebook launched Facebook

Sports Stadium, an interactive hub for fans to interact with games, teams, and players more intimately. In 2017, Amazon outbid Facebook, YouTube, and former rights holder Twitter, for the streaming rights to Thursday Night Football, a one-year deal 
worth a reported $\$ 50 \mathrm{M}$. With introduction through the football, Amazon gathers a myriad of data points on customers and understands the potential for drawing a sports audience that will further explore Amazon's expanding Prime Video service (122).

IBM, a leader in digital transformation, and a Wimbledon and U.S. Open Tennis Championship sponsor and services provider, prioritizes the fan experience, revenue growth, and operational excellence. IBM "fuses strategy, design, data and technology across multiple lines of business to drive superior fan engagement, improve team performance and optimize venue operations. When this vision is put into play, the entire enterprise performs as one streamlined organization, measuring, tracking and responding to real-time data with analytics that drive every opportunity to personalize fan engagement and increase revenue" (117).

Visa, the Official Payment Services Partner of FIFA, enabled contactless payments throughout the 2018 FIFA World Cup stadiums to ensure fans could negotiate lines quickly. In the stadiums fans could pay with contactless Visa credit and debit cards and mobile payment services at over 3,500 point-of-sale terminals and 1,000 mobile concessionaires. In addition, Visa analyzed spending in the first few days of the World Cup and established that one-fifth of purchases throughout Russia for the tournament used contactless technology, including smartphones, bracelets and rings (123).

Digital transformation in the sport industry requires rethinking how sport venues are designed, constructed and operated to align with an integrated approach that addresses the fan experience as well as venue optimization trends.

The success of delivering the right technology depends on: 1) vision and experience-driven requirements development; 2) an information and communication technology (ICT) design team with an end-to-end view of the environment and design requirements; 3 ) a single systems integrator deploying a seamless and secure technology solution. Integrated resource coordination to deliver on time and reduce costs; 4) neutral ownership and control of infrastructure to enable revenue streams and service quality; and 5) integrated venue operations delivering enhanced fan experience and life cycle management (117).

Without question, digital transformation in the sport industry has enhanced the capability of global brands to leverage their brand equity, and increase their ability to communicate across multiple channels with consumers. At the same time, sport and sport sponsorship may actually foster the global diffusion of digital technology.

\section{CONCLUSION}

Sponsorship is a vital part of sports events and it has to deal with lots of cultural restrictions and requirements. The cultural frames of host countries determine what kind of corporations and/or products are allowed to be advertised in sports events. Plus, the way advertisements are used and presented need to be according to the cultural codes of host countries.

While various host countries' cultural frame can put some limitations on any corporation's promotional activities, the organizational culture which exists in a sponsor organization is another factor that can influence the sponsorship outcomes. The more the sponsor organizational culture is matched with the host country cultural values and attitudes, the fewer problems there will be with sponsorship producing effective outcomes. Plus, sports social class and the athlete's social image and sexuality can influence promotional contents and selecting the right sponsor for the events and the athletes.

Symbols and signs are very useful tools to transfer the sponsors' messages without using any words or images. Sponsors can use symbols and signs to inform people about their brand, goals and products and it's a good way when sponsors should act in a special cultural situation. Religious sponsoring can be a good way to attract those people who don't trust commercial sponsorship. Religious organizations can show their social commitments to better societies by supporting sports events.

Sponsorship needs to work with different media but some forms of media are banned in some countries. So corporations should consider such limitations in their commercial efforts in sport events. Moreover, digital transformation is a very important factor influencing on sport venues design, 
consumer experiences and promotional methods and tools sponsors will use in sports events.

The influence of culture on sports sponsorship was the core subject in this article. All the researchers who wrote different parts of this article tried to study sports sponsorship aspects in relation to culture and its components from different new viewpoints. In many parts there was new attitudes towards culture and sponsorship which needs more research and studies in future.
Definitely more research in sponsorship and culture is necessary to make the path of effective sports sponsorship clear for corporation managers and experts to use.

\section{ACKNOWLEDGMENTS}

At the end, special thanks to Vince Moore for editing and correcting this article and making the reading of it easier and more joyful.

\section{REFERENCES}

1. Garcia A. Why sponsors are breaking up with the Olympics: CNN Money; February 17, 2018 [Available from: https://money.cnn.com/2018/02/17/news/companies/olympic-sponsors-mcdonalds-budweiser/index.html.

2. Hobbs T. Olympics 2016: Nissan and Samsung the biggest winners as majority of sponsors fail to ignite: MW Marketing Week; 22 Aug, 2016 [Available from: https://www.marketingweek.com/2016/08/22/olympics-2016nissan-and-samsung-the-biggest-winners-as-majority-of-sponsors-fail-to-ignite/.

3. Price waterhouse Coopers $(\mathrm{PwC})$. At the gate and beyond: Outlook for the sports market in North America through 2021. USA: Price waterhouse Coopers LLP.

4. Meenaghan JA. Commercial Sponsorship. European Journal of Marketing. 1983;17(7):5-73. [DOI:10.1108/EUM0000000004825]

5. Freeman RE, Reed DL. Stockholders and Stakeholders: A New Perspective on Corporate Governance. California Management Review. 1983;25(3):88-106. [DOI:10.2307/41165018]

6. Porter ME, Kramer MR. The big idea: Creating shared value. Harvard Business Review. 2011;89 (1/2):62-77.

7. Crompton JL. Potential negative outcomes from sports sponsorship. International Journal of Sports Marketing and Sponsorship. 2015;16(3):20-34. [DOI:10.1108/IJSMS-16-03-2015-B003]

8. Deloitte Consulting LLP. Deloitte's sports industry starting lineup: Trends expected to disrupt and dominate 2018:
Deloitte
Consulting
LLP;
2018
[Available
from:

https://www2.deloitte.com/content/dam/Deloitte/us/Documents/consumer-business/us-cb-deloitte-sportsbusiness-trends-disruption.pdf.

9. Mandela N. Inaugural speech at the Laureus World Sport Awards: Laureus; 25th May, 2000 [Available from: https://www.laureus.com/content/introduction-laureus.

10. Matsumoto D. The Handbook of Culture and Psychology: Oxford University Press; 2001.

11. Spencer-Oatey H. Culturally speaking: culture, communication and politeness theory. 2nd ed: Continuum; 2008.

12. Fisne M, Gul M. The Importance of Cultural Differences in Global Sports Marketing: Examples from Local Cultures and Global Sports Industry. 12th Annual International Conference on Sports: Economic, Management, Marketing \& Social Aspects; Athens, Greece2012. p. 2.

13. Anastasiadou SD, Vafeiadis T. Study of social influence of publicity with Principal Components Analysis. International Journal of Business and Social Science. 2011;2(8):226-33.

14. Jamaran. Social class influence in sports 2016 [Available from: https://www.jamaran.ir/99327.

15. Markovits AS, Smith DT. Sports culture among undergraduates: A study of student athletes and students at the University of Michigan. University of Michigan Library: Michigan Publishing; 2007.

16. Keshkar S, Ghasemi H, Karegar G. Definition of sports culture and its components regarding to experts, athletes and sport authorities opinions in Iran. Scientific Journal Of Organizational Behavior Management in Sport Studies. 2016;3(4):11-22 [Article in Farsi].

17. World of Rolex. Rolex and Sports: Rolex; 2018 [Available from: https://www.rolex.com/rolex-and-sports.html.

18. Baronet A. Nike's Sports Sponsorship Strategy Barcelona: Esade Alumni; 2008 [Available from: http://www.esadealumni.net/ea/activities/detalle eventos_pasados?id_evento=80381.

19. Marketbl. Case Study: Nike's Marketing Strategy 2017 [Available from: http://marketbl.com/blog/case-studynikes-marketing-strategy.

20. USA Wrestling. About-Us/Sponsors: teamusa.org; n.d. [Available from: https://www.teamusa.org/USAWrestling/About-Us/Sponsors.

21. U.S. Soccer. Official Sponsors: United States Soccer Federation Inc; n.d. [Available from: https://www.ussoccer.com/about/sponsors.

22. Trachsler T, DeGaris L, Dodds M. Sport commercialism and its impact on sponsorship strategy. Sports Management International Journal: Choregia. 2015;11(2):77-92. [DOI:10.4127/ch.2015.0103] 
23. McCarville RE, Copeland RP. Understanding Sport Sponsorship through Exchange Theory. Journal of Sport Management. 1994;8(2):102-14. [DOI:10.1123/jsm.8.2.102]

24. Madrigal R. The Influence of Social Alliances with Sports Teams on Intentions to Purchase Corporate Sponsors' Products. Journal of Advertising. 2000;29(4):13-24. [DOI:10.1080/00913367.2000.10673621]

25. Crompton JL. Potential negative outcomes from sponsorship for a sport property. Managing Leisure. 2014;19(6):420-41. [DOI:10.1080/13606719.2014.912050]

26. Dodds M, Rasku R, Laitila O. Corruption impact on sport sponsorship strategy. Sports Management International Journal : Choregia. 2018;14(1):21-33. [DOI:10.4127/ch.2018.0127]

27. Uhrich S, Koenigstorfer J, Groeppel-Klein A. Leveraging sponsorship with corporate social responsibility. Journal of Business Research. 2014;67(9):2023-9. [DOI:10.1016/j.jbusres.2013.10.008]

28. Szykman LR, Bloom PN, Blazing J. Does Corporate Sponsorship of a Socially-Oriented Message Make a Difference? An Investigation of the Effects of Sponsorship Identity on Responses to an Anti-Drinking and Driving Message. Journal of Consumer Psychology. 2004;14(1):13-20. [DOI:10.1207/s15327663jcp1401\&2 3]

29. Walker M, Hills S. Social program evaluations: Strategies and shared value. Sport \& Entertainment Review. 2017;3:65-71.

30. Cornwell B. Soliciting Sport Sponsorship. In: Bradbury T, O'Boyle I, editors. Understanding Sport Management: International perspectives: Taylor \& Francis; 2017.

31. Alvesson M. Understanding organizational culture. 2nd ed. London: Sage; 2013. 236 p. [PMCID]

32. Dietl HM, Özdemir A, Schweizer N. Outsourcing sports sponsorship activities: a multi-theoretical approach. Sport, Business and Management: An International Journal. 2017;7(1):77-96. [DOI:10.1108/SBM-09-2014-0041]

33. Nufer G, Bühler A. Establishing and maintaining win-win relationships in the sports sponsorship business. Journal of Sponsorship. 2010;3(2):157-68.

34. Morgan A, Adair D, Taylor T, Hermens A. Sport sponsorship alliances: relationship management for shared value. Sport, Business and Management: An International Journal. 2014;4(4):270-83. [DOI:10.1108/SBM-12-20130044]

35. Jensen JA, Cornwell TB. Why Do Marketing Relationships End? Findings From an Integrated Model of Sport Sponsorship Decision-Making. Journal of Sport Management. 2017;31(4):401-18. [DOI:10.1123/jsm.2016-0232]

36. Payne M. Olympic Turnaround. 1st ed. London, UK: London Business Press; 2005.

37. Keller C. Steuerung von Fußballunternehmen: Finanziellen und sportlichen Erfolg langfristig gestalten. 1st ed. Berlin: Erich Schmidt Verlag GmbH \& Co; 2008. 381 p.

38. Meenaghan T. The Role of Sponsorship in the Marketing Communications Mix. International Journal of Advertising. 1991;10(1):35-47. [DOI:10.1080/02650487.1991.11104432]

39. Richards JI, Catharine MC. Oracles on "Advertising": Searching for a Definition. Journal of Advertising. 2002;31(2):63-77. [DOI:10.1080/00913367.2002.10673667]

40. Zafer Erdogan B, Kitchen PJ. Managerial mindsets and the symbiotic relationship between sponsorship and advertising. Marketing Intelligence \& Planning. 1998;16(6):369-74. 41. Crimmins J, Horn M. Sponsorship: From management ego trip to marketing success. Journal of Advertising Research. 1996;36(4):11-22. [DOI:10.1108/02634509810237578]

41. Tan SJ, Chia L. Are we measuring the same attitude? Understanding media effects on attitude towards advertising. Marketing Theory. 2007;7(4):353-77. [DOI:10.1177/1470593107083162]

42. Pyun DY, James JD. Attitude toward advertising through sport: A theoretical framework. Sport Management Review. 2011;14(1):33-41. [DOI:10.1016/j.smr.2009.12.002]

43. Jackson SJ, Andrews DL. Sport, Culture and Advertising: Identities, Commodities and the Politics of Representation. 1st ed: Taylor \& Francis; 2005. 288 p. [DOI:10.4324/9780203462003]

44. Lopez-Gonzalez H, Guerrero-Solé F, Griffiths MD. A content analysis of how 'normal' sports betting behaviour is represented in gambling advertising. Addiction Research \& Theory. 2018;26(3):238-47. [DOI:10.1080/16066359.2017.1353082]

45. Scherer J, Jackson SJ. Sports Advertising, Cultural Production and Corporate Nationalism at the Global-Local Nexus: Branding the New Zealand All Blacks. Sport in Society. 2007;10(2):268-84. [DOI:10.1080/17430430601147112]

46. Westberg K, Stavros C, Smith ACT, Munro G, Argus K. An examination of how alcohol brands use sport to engage consumers on social media. Drug and Alcohol Review. 2018;37(1):28-35. [DOI:10.1111/dar.12493] [PMID]

47. Aswad C. Women in sports ad strikes nerve in Arab world: Reuters; February 23, 2017 [Available from: https://www.reuters.com/article/us-arab-women-nike/women-in-sports-ad-strikes-nerve-in-arab-worldidUSKBN1620I7. 
48. Sponsorship.com. Press Room: Press Releases: FIFA Secures \$1.6 Billion in World Cup Sponsorship Revenue: Sponsorship.com; 2010 [Available from: http://www.sponsorship.com/About-IEG/Press-Room/FIFA-Secures-\$16-Billion-in-World-Cup-Sponsorship.aspx.

49. FIFA.com. About FIFA: FIFA Partners: FIFA; n.d. [Available from: https://www.fifa.com/aboutfifa/marketing/sponsorship/partners/index.html.

50. Irwin RL, Sutton WA, McCarthy LM. Sport Promotion and Sales Management. 2nd ed: Human Kinetics; 2008. $339 \mathrm{p}$.

51. Javalgi RG, Traylor MB, Gross AC, Edward L. Awareness of Sponsorship and Corporate Image: An Empirical Investigation. Journal of Advertising. 1994;23(4):47-58. [DOI:10.1080/00913367.1943.10673458]

52. Gwinner KP, Eaton J. Building Brand Image through Event Sponsorship: The Role of Image Transfer. Journal of Advertising. 1999;28(4):47-57. [DOI:10.1080/00913367.1999.10673595]

53. Scott DR, Suchard HT. Motivations for Australian Expenditure on Sponsorship-An Analysis. International Journal of Advertising. 1992;11(4):325-32. [DOI:10.1080/02650487.1992.11104508]

54. Sen S, Bhattacharya CB. Does Doing Good Always Lead to Doing Better? Consumer Reactions to Corporate Social Responsibility. Journal of Marketing Research. 2001;38(2):225-43. [DOI:10.1509/jmkr.38.2.225.18838]

55. Miyazaki AD, Morgan AG. Assessing the Market Value of Sponsoring: Corporate Olympic Sponsorships. Journal of Advertising Research. 2001;41(1):9. [DOI:10.2501/JAR-41-1-9-15]

56. Madrigal R. Social identity effects in a belief-attitude-intentions hierarchy: Implications for corporate sponsorship. Psychology \& Marketing. 2001;18(2):145-65. https://doi.org/10.1002/1520-6793(200102)18:2<145::AIDMAR1003>3.0.CO;2-T [DOI:10.1002/1520-6793(200102)18:23.0.CO;2-T]

57. Burden-Hamer H, Emirates Group. Emirates gets Benfica fans on their feet: Emirates Group; 27 October, 2015 [Available from: https://www.emirates.com/media-centre/emirates-gets-benfica-fans-on-their-feet.

58. Juventus.com. Club. Partners. Jeep n.d. [Available from: http://www.juventus.com/en/club/partners/jeep.php.

59. Jeep.com. Jeep | Juventus: Jeep.com; n.d. [Available from: http://www.juventus.jeep.com/en/global/.

60. Chanavat N, Desbordes M, Dickson G. Sponsorship networks: toward an innovative model. Sport, Business and Management: An International Journal. 2016;6(4):424-39. [DOI:10.1108/SBM-12-2015-0041]

61. Chandler J. Sport is not a religion. In: Hoffman J, editor. Sport and Religion. Champaign, IL: Human Kinetics; 1992. p. 55-61.

62. Hoffman SJ. Good game: Christianity and the culture of sports: Baylor University Press; 2010. 341 p.

63. Stolz J, Usunier J-C. Religions as brands? Religion and spirituality in consumer society. Journal of Management, Spirituality \& Religion. 2018:1-26. [DOI:10.1080/14766086.2018.1445008]

64. Lee S. Marketing through sport: a case of a religious organization. International Review on Public and Nonprofit Marketing. 2010;7(1):87-96. [DOI:10.1007/s12208-009-0043-8]

65. Nite C, Singer JN, Cunningham GB. Addressing competing logics between the mission of a religious university and the demands of intercollegiate athletics. Sport Management Review. 2013;16(4):465-76. [DOI:10.1016/j.smr.2013.03.002]

66. Cunningham S, Cornwell TB, Coote LV. Expressing Identity and Shaping Image: The Relationship between Corporate Mission and Corporate Sponsorship. Journal of Sport Management. 2009;23(1):65-86. [DOI:10.1123/jsm.23.1.65]

67. Butterworth M, Senkbeil K. Cross-cultural comparisons of religion as "character": Football and soccer in the United States and Germany. International Review for the Sociology of Sport. 2015;52(2):129-45. [DOI:10.1177/1012690215588214]

68. Mansour IHF, Diab DME. The relationship between celebrities' credibility and advertising effectiveness: The mediation role of religiosity. Journal of Islamic Marketing. 2016;7(2):148-66. [DOI:10.1108/JIMA-05-2013-0036]

69. Dun S. No beer, no way! Football fan identity enactment won't mix with Muslim beliefs in the Qatar 2022 World Cup. Journal of Policy Research in Tourism, Leisure and Events. 2014;6(2):186-99. [DOI:10.1080/19407963.2014.925256]

70. Cox M, Dickson G, Cox B. Lifting the veil on allowing headscarves in football: A co-constructed and analytical autoethnography. Sport Management Review. 2017;20(5):522-34. [DOI:10.1016/j.smr.2017.08.005]

71. Xie G-X, Atay EG, Kahle LR, Ring K, editors. Effective Advertising Decisions in Television Sports Programs. Proceedings of the 2007 Academy of Marketing Science (AMS) Annual Conference; 2015 2015//; Cham: Springer International Publishing. [DOI:10.1007/978-3-319-11806-2_122]

72. Holland CP, editor Internet and Social Media Strategy in Sports Marketing. Twenty-Third European Conference on Information Systems (ECIS); 2015; Münster, Germany: Association for Information Systems (AIS) Electronic Library (AISeL).

73. Neti S. Social media and its role in marketing. International Journal of Enterprise Computing and Business Systems. 2011;1(2):1-15. 
74. Sajid S. Social Media and Its Role in Marketing. Business and Economics Journal. 2016;7(1):1000203.

75. Husain S, Ghufran A, Chaubey DS. Relevance of social media in marketing and advertising. Splint International Journal of Professionals. 2016;3(7):21-8.

76. Horák T. Influence of Mass Media, Marketing and Advertising on Development of Sports: State University of New York; 2016.

77. SLC Team. List of Websites and Apps Blocked in China [Updated Aug 2018]: Startup Living China; 10 August, 2018 [Available from: https://startuplivingchina.com/list-websites-apps-blocked-china/.

78. Bernstein A, Blain N. Sport and the Media: The Emergence of a Major Research Field. Culture, Sport, Society. 2002;5(3):1-30. [DOI:10.1080/911094213]

79. Boyle R, Haynes R. Power Play: Sport, the Media and Popular Culture. 2nd ed: Edinburgh University Press; 2009. 254 p. 81. Summers J, Johnson Morgan M. More than just the media: Considering the role of public relations in the creation of sporting celebrity and the management of fan expectations. Public Relations Review. 2008;34(2):176-82. [DOI:10.3366/edinburgh/9780748635924.001.0001]

80. Brown WJ, de Matviuk MAC. Sports Celebrities and Public Health: Diego Maradona's Influence on Drug Use Prevention. Journal of Health Communication. 2010;15(4):358-73. [DOI:10.1080/10810730903460575] [PMID]

81. Fraser BP, Brown WJ. Media, Celebrities, and Social Influence: Identification With Elvis Presley. Mass Communication and Society. 2002;5(2):183-206. [DOI:10.1207/S15327825MCS0502 5]

82. Knowlton E. LeBron James' business partner confirms lifetime deal with Nike is worth over $\$ 1$ billion: Business Insider UK; May 17, 2016 [Available from: http://uk.businessinsider.com/lebron-james-nike-deal-exceeds-1billion-maverick-carter-says-2016-5.

83. Heitner D. Sports Industry To Reach $\$ 73.5$ Billion By 2019: Forbes; Oct 19, 2015 [Available from: https://www.forbes.com/sites/darrenheitner/2015/10/19/sports-industry-to-reach-73-5-billion-by2019/\#3096ae391b4b.

84. Bryan B. MORGAN STANLEY: Stephen Curry could be worth $\$ 14$ billion: Business Insider; 2016, 30 September [Available from: https://www.businessinsider.com.au/steph-curry-worth-14-billion-to-under-armour-20163? $\mathrm{r}=\mathrm{US} \& \mathrm{IR}=\mathrm{T}$.

85. Kahle LR, Homer PM. Physical Attractiveness of the Celebrity Endorser: A Social Adaptation Perspective. Journal of Consumer Research. 1985;11(4):954-61. [DOI:10.1086/209029]

86. Kamins MA. An Investigation into the "Match-up" Hypothesis in Celebrity Advertising: When Beauty May Be Only Skin Deep. Journal of Advertising. 1990;19(1):4-13. [DOI:10.1080/00913367.1990.10673175]

87. Ohanian R. The impact of celebrity spokespersons' perceived image on consumers' intention to purchase. Journal of Advertising Research. 1991;31(1):46-54.

88. Elberse A, Jeroen V. The Economic Value of Celebrity Endorsements. Journal of Advertising Research. 2012;52(2):149-65. [DOI:10.2501/JAR-52-2-149-165]

89. Kelly SJ, Weeks CS, Chien PM. There goes my hero again: sport scandal frequency and social identity driven response. Journal of Strategic Marketing. 2018;26(1):56-70. [DOI:10.1080/0965254X.2017.1359656]

90. Isidore C, Wattles J. Ryan Lochte ditched by four major sponsors: CNN Money; August 22, 2016 [Available from: https://money.cnn.com/2016/08/22/news/companies/ryan-lochte-speedo/.

91. Knittel CR, Stango V. Celebrity Endorsements, Firm Value, and Reputation Risk: Evidence from the Tiger Woods Scandal. Management Science. 2013;60(1):21-37. [DOI:10.1287/mnsc.2013.1749]

92. Smyth J. Sponsors cut ties with Australian cricket after cheating scandal: Financial Times; March 29, 2018 [Available from: https://www.ft.com/content/411debb2-32f5-11e8-b5bf-23cb17fd1498.

93. Vredenburg J, Giroux M. What did Ryan Lochte do? The double-edged sword of endorsers behaving badly. International Journal of Sports Marketing and Sponsorship. 2018;19(3):290-305. [DOI:10.1108/IJSMS-02-20170012]

94. Chung KYC, Derdenger TP, Srinivasan K. Economic Value of Celebrity Endorsements: Tiger Woods' Impact on Sales of Nike Golf Balls. Marketing Science. 2013;32(2):271-93. [DOI:10.1287/mksc.1120.0760]

95. Chen C-Y, Claussen CL, Lin Y-H. Celebrity endorsement for sporting events using classical conditioning. International Journal of Sports Marketing and Sponsorship. 2012;13(3):46-56. [DOI:10.1108/IJSMS-13-03-2012B005]

96. Bee C, Dalakas V. Rivalries and sponsor affiliation: Examining the effects of social identity and argument strength on responses to sponsorship-related advertising messages. Journal of Marketing Communications. 2015;21(6):40824. https://doi.org/10.1080/13527266.2013.860260 [DOI:10.1080/13527266.2013.828768]

97. Knoll J, Matthes J. The effectiveness of celebrity endorsements: a meta-analysis. Journal of the Academy of Marketing Science. 2017;45(1):55-75. [DOI:10.1007/s11747-016-0503-8]

98. Meng J, Pan P-L. Revisiting Image-Restoration Strategies: An Integrated Case Study of Three Athlete Sex Scandals in Sports News. International Journal of Sport Communication. 2013;6(1):87-100. [DOI:10.1123/ijsc.6.1.87] 
99. Carlson BD, Donavan DT. Be Like Mike: The Role of Social Identification in Athlete Endorsements. Sport Marketing Quarterly. 2017;26(3):176-91.

100. Gorse S, Chadwick S. Conceptualising corruption in sport: Implications for sponsorship programmes. The European Business Review. 2010:40-5.

101. SPORTS NEWS. Balotelli to have good behaviour clause in Milan contract: Reuters; AUGUST 26, 2015 [Available from: https://uk.reuters.com/article/uk-soccer-italy-milan-balotelli/balotelli-to-have-good-behaviourclause-in-milan-contract-idUKKCN0QV0QU20150826.

102. Sato S, Ko YJ, Chang Y, Kay M. How Does the Negative Impact of an Athlete's Reputational Crisis Spill Over to Endorsed and Competing Brands? The Moderating Effects of Consumer Knowledge. Communication \& Sport. 2018:2167479518783461.

103. Mottier V. Sexuality: A Very Short Introduction. 1st ed. New Yourk: Oxford University Press; 2008.156 p. [DOI:10.1093/actrade/9780199298020.001.0001] [PMCID]

104. Jensen JA, Turner B. Advances in Sport Sponsorship Revenue Forecasting: An Event History Analysis Approach. Sport Marketing Quarterly. August 29, 2016;Forthcoming(Forthcoming):https://ssrn.com/abstract=2914372.

105. Lee M. Naming gay All Blacks marks sexuality, not talent: New Zealand Herald; 14 Jan, 2013 [Available from: https://www.nzherald.co.nz/nz/news/article.cfm?c id=1\&objectid=10858894.

106. Kane MJ, LaVoi NM, Fink JS. Exploring Elite Female Athletes' Interpretations of Sport Media Images: A Window Into the Construction of Social Identity and "Selling Sex" in Women's Sports. Communication \& Sport. 2013;1(3):269-98. [DOI:10.1177/2167479512473585]

107. Bass J, Hardin R, Taylor EA. The Glass Closet: Perceptions of Homosexuality in Intercollegiate Sport. Journal of Applied Sport Management. 2015;7(4):1-31. [DOI:10.18666/JASM-2015-V7-I4-5298]

108. Anderson E. Sport, Masculinities and Sexualities. 1st ed. New York: Taylor \& Francis; 2013. 202 p.

109. Melton EN, Cunningham GB. Examining the Workplace Experiences of Sport Employees Who Are LGBT: A Social Categorization Theory Perspective. Journal of Sport Management. 2014;28(1):21-33. [DOI:10.1123/jsm.2011-0157]

110. McCormack M. Mapping the Terrain of Homosexually-Themed Language. Journal of Homosexuality. 2011;58(5):664-79. [DOI:10.1080/00918369.2011.563665] [PMID] [PMCID]

111. Logue M. Russia picks the wrong fight: How will sponsors respond? SBJ SportsBusiness Journal: SBD SportsBusiness Daily; October 28, 2013 [Available from: https://www.sportsbusinessdaily.com/Journal/Issues/2013/10/28/Opinion/Matthew-Logue.aspx.

112. Cunningham G, Melton EN. The benefits of sexual orientation diversity in sport organizations. In: Anderson E, editor. Sport, Masculinities and Sexualities. 1st ed. New York: Taylor \& Francis; 2013. p. 103-19.

113. Cleland J. Sexuality, masculinity and homophobia in association football: An empirical overview of a changing cultural context. International Review for the Sociology of Sport. 2016;53(4):411-23. [DOI:10.1177/1012690216663189]

114. i-SCOOP. Digital transformation: online guide to digital transformation: i-SCOOP; [Available from: https://www.i-scoop.eu/digital-transformation/.

115. Short J. IBM Leads Digital Transformation in Sports: IT Biz Advisor; 12 July, 2017 [Available from: https://itbizadvisor.com/2017/07/ibm-leads-digital-transformation-in-sports/.

116. Lalli F. Sport Digital Transformation: the new direction of Customer and Fan Experience: Medium Corporation; May 14, 2018 [Available from: https://medium.com/iquii/sport-digital-transformation-the-new-direction-ofcustomer-and-fan-experience-9eca0605156d.

117. Bacon J. How sport sponsorship is joining the digital age: MW Marketing Week; 22 Apr 2015 [Available from: https://www.marketingweek.com/2015/04/22/how-sport-sponsorship-is-joining-the-digital-age/.

118. Zencka D. Let the social and mobile games begin: Iprospect.com; 2012, August 7 [Available from: http://www.iprospect.com/tag/social-media-olympics.

119. Carpenter R. Real-Time Marketing Isn't What You Think It Is: Evergage; June 15, 2014 [Available from: https://www.evergage.com/blog/real-time-marketing-isnt-what-you-think-it-is/.

120. Stewart J. Digital Transformation in Sports and Entertainment: CSQ; 2017, July 25 [Available from: https://csq.com/2017/07/jeffrey-stewart-digital-transformation-sports-entertainment/\#.W8CgW2hKhPY.

121. Gazdik T. Visa Finds Contactless Payment Catches On At FIFA World Cup: Media Post; June 29, 2018 [Available from: https://www.mediapost.com/publications/article/321516/visa-finds-contactless-payment-catches-on-atfifa.html. 